\title{
ACKNOWLEDGMENTS
}

I first met Tim and Karen Hixon twenty-five years ago when we ran the Snake River in Idaho through the Birds of Prey Natural Area. We shared an extraordinary experience on the river and have remained close friends and allies in conservation ever since. Tim and Karen are among the most unassuming people I know, yet their combined contributions to our movement in time, leadership, philanthropy, and just plain encouragement reach well beyond Texas to all parts of the world. They are the second couple ever to have served on the prestigious Texas Parks and Wildlife Commission, and without their underwriting this book would not have been possible. I am grateful to them for that, of course, and for all they have done for the outdoors, but I am most grateful that my kids got to know two such fine human beings.

Many other people contributed to this book in many ways. It is truly a collaboration. My longtime colleague, Emily Armitano, served as a kind of producer, taskmaster, and editor; and Tom Wassenich headed up the research. 
Our team was fortunate to have funding from the Meadows Foundation and to have had the benefit of a number of expert reviewers, including Rich Earl, Warren Pulich, Joni Charles, Norman Johns, David Bradsby, Cindy Loeffler, Jason Pinchback, and Myron Hess. The graphics were skillfully executed by two of my students, Eduardo Valdez and Jessica Spangler. Two other talented students, Mary Waters and Lauren Bilbe, fact-checked the text. Chad Norris, Jennifer Ellis, Tyson Broad, Fran Sage, and Susan Romanella helped whenever we called on them.

I am deeply grateful to Wyman Meinzer, the Texas Parks and Wildlife Department, Blake Matejowski, Gregg Eckhart, and several others for the many wonderful images that help to tell this story so well.

Finally, working with the University of Texas Press is a pleasure, thanks to Bill Bishel and his team, including Megan Giller. This is my second project with them; I truly hope it will not be the last. My heartfelt thanks to everyone who made this book possible. 


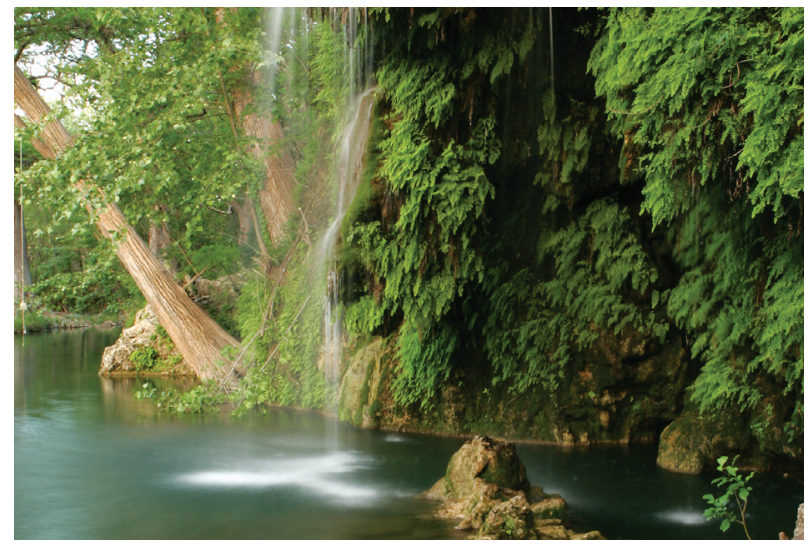

\section{WATER IN TEXAS}




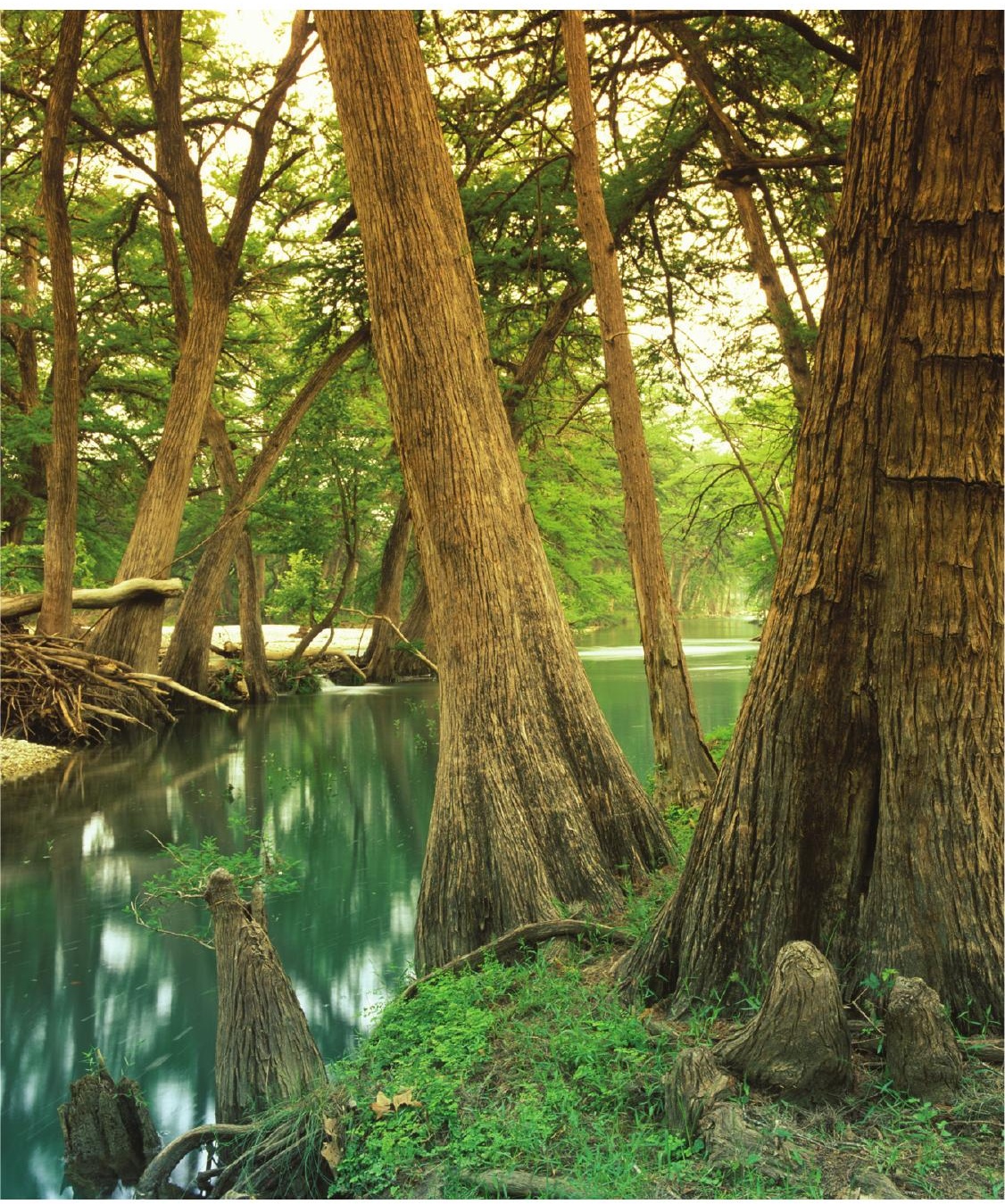

Cypress trees line the Sabinal River.

Photo by Wyman Meinzer. 